\title{
Management of erectile dysfunction post-radical prostatectomy
}

\author{
This article was published in the following Dove Press journal: \\ Research and Reports in Urology \\ 23 February 2015 \\ Number of times this article has been viewed
}

\section{Alan Saleh \\ Hamid Abboudi \\ MB Ghazal-Aswad \\ Erik K Mayer \\ Justin A Vale}

Division of Surgery and Cancer Imperial College Healthcare NHS

Trust, St Mary's Hospital, London, UK
Correspondence: Hamid Abboudi Division of Surgery and Cancer, Imperial College Healthcare NHS Trust, St Mary's Hospital, Praed Street, London W2 INY, UK

Tel +442033I2 6666

Fax +442082968789

Email hamid.abboudi@doctors.org.uk

\begin{abstract}
Radical prostatectomy is a commonly performed procedure for the treatment of localized prostate cancer. One of the long-term complications is erectile dysfunction. There is little consensus on the optimal management; however, it is agreed that treatment must be prompt to prevent fibrosis and increase oxygenation of penile tissue. It is vital that patient expectations are discussed, a realistic time frame of treatment provided, and treatment started as close to the prostatectomy as possible. Current treatment regimens rely on phosphodiesterase 5 inhibitors as a first-line therapy, with vacuum erection devices and intraurethral suppositories of alprostadil as possible treatment combination options. With nonresponders to these therapies, intracavernosal injections are resorted to. As a final measure, patients undergo the highly invasive penile prosthesis implantation. There is no uniform, objective treatment program for erectile dysfunction post-radical prostatectomy. Management plans are based on poorly conducted and often underpowered studies in combination with physician and patient preferences. They involve the aforementioned drugs and treatment methods in different sequences and doses. Prospective treatments include dietary supplements and gene therapy, which have shown promise with there proposed mechanisms of improving erectile function but are yet to be applied successfully in human patients.
\end{abstract}

Keywords: erectile dysfunction, phosphodiesterase 5 inhibitors, vacuum erection devices, intraurethral suppositories, intracavernosal injections

\section{Introduction}

Radical prostatectomy (RP) remains the most commonly employed procedure for localized prostate cancer in patients with a life expectancy of at least 10 years. ${ }^{1}$ More than 4,000 patients undergo RP yearly in the UK for localised prostate cancer. ${ }^{2}$ Common complications associated with RP include the development of erectile dysfunction (ED). ED and reduced sexual satisfaction have a negative impact on quality of life even after initial treatment for cancer. ${ }^{3}$ Potency rates vary greatly between $14 \%$ and $90 \%$. ${ }^{1,3}$ The reasons for this large discrepancy in rates of post-RP ED relate to variations in the nature of the populations studied as well as differences in data collection and reporting. Another recurring problem is the lack of an objective, reliable, and universal definition of erectile function (EF), both prior to and after surgery. ${ }^{1}$ Current literature demonstrates inconsistency in how to define "normal" EF, and this has obvious consequences when discussing management and progress with patients. The percentage of patients who develop post-RP ED depends on several factors, including patient age, preoperative potency status (baseline EF), comorbidities, extension of nerve-sparing RP (unilateral vs bilateral), type of surgery (intra- vs inter- vs extrafascial), surgical technique (open 
vs laparoscopic vs robot-assisted RP), and level of surgical experience. ${ }^{1}$ Of greater relevance to this review, there is little consensus as to the optimal management pathway of post-RP ED; this has been the case since the nerve-sparing RP was introduced by Walsh et al over 30 years ago. ${ }^{1,3,4}$ It is evident that minimizing and reversing post-RP ED remains a major challenge for urologists, and therefore reviewing the management options is of great importance. This review provides an overview of the management of ED post-RP.

\section{Pathophysiology of erectile dysfunction following nerve- sparing radical prostatectomy}

A thorough understanding of the pathogenesis of post-RP $\mathrm{ED}$ is required in order to fully comprehend the rationale behind different therapies. During sexual stimulation, nitric oxide (NO) from the cavernosal nerves is released, leading to an increase in oxygenated blood flow to the penis. Vascular and sinusoidal forces on the endothelium lead to a sustained nitric oxide synthase (eNOS) release from endothelial cells (Table 1). This mechanism is crucial for erection prior to intercourse as well as the long-term maintenance of corporal health. A reduction in tissue oxygenation leads to a decrease in NO production, and this in turn leads to inhibition of prostaglandin release. This has an important role in protecting smooth muscle through inhibition of accumulation of profibrotic substances (such as collagen I and III). Prolonged hypoxia will result in connective tissue buildup, which will eventually replace more elastic trabecular smooth muscle. These fibrotic changes make it increasingly challenging for the penis to expand on stimulation through the mechanisms described above. ${ }^{5}$ RP exacerbates these changes or may even initiate them in younger patients undergoing the procedure. Even in the hands of the most experienced surgeon, a degree of cavernosal nerve damage occurs during prostatectomy. ${ }^{6}$ The main mechanism through which this is thought to occur

Table I Nitric oxide synthase (NOS) subtypes

\begin{tabular}{lll}
\hline Type & Location & Function \\
\hline Endothelial & Vascular endothelial & Vasodilation \\
NOS/eNOS & cells & $\begin{array}{l}\text { Vasoprotection } \\
\text { Atherosclerosis prevention }\end{array}$ \\
Inducible & Macrophages & Nonspecific immune defense \\
NOS/iNOS & & Mediation of inflammation \\
Neuronal & Neuronal tissue & Septic shock \\
NOS/nNOS & & Synaptic plasticity \\
& & Blood pressure regulation \\
& & Atypical neurotransmission \\
\hline
\end{tabular}

Note: Data from. ${ }^{8}$ is neuropraxia. The exact etiology of neuropraxia is a matter of debate, but hypotheses include direct trauma during surgery, thermal damage due to electrocautery, cavernous nerve ischemia due to vascular injury (such as the accessory pudendal arteries), and local inflammatory effects associated with the procedure. ${ }^{3,7}$

Overall, EF is impacted post-RP by interference with the nerve function that facilitates cavernosal oxygenation. In time, fibrosis ensues, and this is manifested by the presence of transforming growth factor $\beta$ (TGF- $\beta$ ) - a marker of chronic inflammation and fibrosis. ${ }^{3}$ Simultaneously, production of antifibrotic mediators prostaglandin E1 (PGE1) and cyclic adenosine monophosphate (cAMP) ceases, and there is no resultant inhibition of TGF- $\beta 1$-induced collagen synthesis. ${ }^{9}$ In addition, synthesis of endothelin-1 (ET-1) (a potent constrictor of penile smooth muscle) is amplified by TGF- $\beta 1$ and prolonged hypoxia. While neuropraxia is, fortunately, reversible, the product of fibrosis, cavernosal smooth muscle apoptosis, is not. This is why timely treatment of post-RP ED is vital. ${ }^{3}$

It is possible that the deposition of collagen is due to cellular apoptosis of smooth muscle (not of the endothelium), particularly in the subtunical area, causing dysfunction of the veno-occlusive mechanism of the corpus cavernosum. These mechanisms underlie the etiology of the massive corporeal venous leaks that follow. ${ }^{6}$ The damage manifests itself as chronic ED. To counter the fibrosis, early tissue oxygenation is paramount, and this serves as the rationale behind the majority of management options.

\section{Managing patient expectations and objectives of management}

The International Consensus of Sexual Medicine (ICSM) recommends the application of psychometric tools to yield a better understanding of the patient-specific EF pre- and post-RP. Highly recommended psychometric tools are the International Index of Erectile Function (IIEF) (Table S1) or the Sexual Health Inventory for Men (SHIM) (Table S2), with cutoff scores for "normal" EF being 26 and 21, respectively. This will help both patients and professionals understand how to prevent damage and tackle recovery while reducing false expectations. In addition, knowledge of potential use of preoperative erectogenic aids is of great value. ${ }^{1}$ All patients should undergo a detailed evaluation to establish their level of EF presurgery. This includes applying psychometric tools along with a detailed sexual history. ${ }^{5}$

Patient expectations should be explored prior to discussion of different management approaches and outcomes. Expectations for both patients and professionals are usually 
high, with reports of an average of only $50 \%-60 \%$ of patients returning to their approximate baseline score at 1 year (based on the IIEF score). ${ }^{4}$ Realistically, a patient will not retain the ability to create spontaneous and nocturnal erections within the first few months regardless of how aggressive the treatment is. Thus, another important factor in preventing false expectations is providing patients with a realistic time frame for recovery of EF. Experts suggest a period of 6-36 months would be necessary; however, most individuals will experience functional recovery within 12-24 months post-RP. ${ }^{1,10}$

Recovery of function can occur only through a rehabilitation process that prevents fibrosis and end-organ damage while the nerves and vasculature recover. This needs to be communicated well to the patient, as many patients will become discouraged by the lack of progress. ${ }^{5}$

It is very important that the partners of patients be incorporated in the consultation and treatment process. This is in line with recent findings that a divergence in attitude and expectations between both partner and patient may render the treatment process futile. High expectations might cause sexual anxiety in patients who are unable to meet their partners' needs. As such, the presence of partners in counseling may prevent this from happening, by encouraging the discussion of frustrations. In addition, cooperative partners maintained sexual desire in patients compared with noncooperative ones, who created less sexual motivation in patients post-RP. ${ }^{11,12}$

Also worth communicating to the patient are prognostic indicators. One excellent prognostic indicator is the ability to have either a spontaneous or a pharmacologically assisted functional erection within 3 months post-RP. ${ }^{1}$

\section{Postoperative treatment}

Many different treatment strategies have been devised to improve EF in post-RP patients. Although there is little consensus with regard to the best strategy, treatment is undoubtedly better than leaving the tissue unassisted. Evidence suggests that the incidence of veno-occlusive dysfunction increases in a time-dependent fashion post-RP. The following management options have been listed by the ICSM committee in combination or as stand-alone therapies: regular oral phosphodiesterase type5 inhibitors (PDE5), vacuum erection devices (VEDs), intraurethral alprostadil suppository (MUSE $^{\circledR}$, Vivus Inc., Mountain View, CA, USA), intracavernosal injections (ICIs), and neuromodulatory agents. The ICSM committee is unable to recommend specific, optimal rehabilitation regimens, and therefore these therapies are utilized differently in practice. Penile implants are reserved for a specific cohort of patients when less invasive treatments have failed. Evidence-based, expert opinion also supports early treatment for better long-term outcomes. ${ }^{13}$ The literature emphasizes that any form of rehabilitation or treatment should be initiated as close to the surgery as possible.

\section{Phosphodiesterase type 5 inhibitors}

As already mentioned, there is evidence to suggest apoptotic processes taking place in the smooth muscle of the penis following cavernosal nerve injury. Therefore, both smooth muscle fibrosis and atrophy in cavernosal tissue may occur owing to the cessation of key growth factor production by cavernosal nerves. Instead, there is production of proapoptotic cytokines and reactive oxygen species by damaged nerves. Unsurprisingly, cavernosal tissue counteracts this mechanism through endogenous production of inducible nitric oxide synthase (iNOS) and its secondary messenger, cyclic guanosine monophosphate (cGMP). As PDE5 works by inhibiting the degradation of cGMP and subsequently increasing blood flow to the penis, it has a theoretical application in post-RP ED. ${ }^{9}$ This process will, at least hypothetically, yield a higher level of oxygenated blood flow to the corpora cavernosa, which in turn is needed for NO production - and thus prevention of connective tissue formation. Despite these beneficial effects, precautions must be taken when administering PDE5 in view of the adverse effects of these same vasodilatory characteristics on capillary systems running in smooth muscle structures in other parts of the body (Table 2). Similarly, these same characteristics make their concurrent administration with organic nitrates unfeasible. This is because when nitrates are given at the same time as PDE5 inhibitors (PDE5i), there is both an increase in the production of cGMP (due to the NO donor) and an inhibition of its breakdown (due to the PDE5i) that can lead to a buildup of cGMP with pronounced vasodilation and, in some patients, hypotension. ${ }^{14}$ Significant hypotension occurs once again

Table 2 Common ( $>1 \%$ ) side effects of the phosphodiesterase type 5 inhibitors

\begin{tabular}{llll}
\hline Common side effects & Sildenafil & Vardenafil & Tadalafil \\
\hline Headache & $\checkmark$ & $\checkmark$ & $\checkmark$ \\
Dyspepsia & $\checkmark$ & $\checkmark$ & $\checkmark$ \\
Dizziness & $\checkmark$ & $\checkmark$ & $\checkmark$ \\
Flushing & $\checkmark$ & & $\checkmark$ \\
Nasal congestion & $\checkmark$ & $\checkmark$ & $\checkmark$ \\
Rhinitis & & & \\
Altered vision & $\checkmark$ & \\
Back pain, myalgia & &
\end{tabular}

Note: Data from. ${ }^{15}$ 
on using vardenafil or tadalafil with $\alpha$-blockers (Table 3). Conclusively, $\alpha$-blockers are contraindicated. ${ }^{15}$

There is histological evidence from rat models to suggest improvement of EF and preservation of cavernosal smooth muscle integrity after cavernous nerve injury when supplemented with PDE5i. ${ }^{16}$ In a similar animal study, it has also been shown that chronic administration of PDE5i limits apoptosis by improving the smooth muscle/collagen ratio in corporal tissue. ${ }^{5}$ The animal study looked at resection or crush injuries to the cavernosal nerve rather than neuropraxia secondary to prostatectomy. ${ }^{5}$

Evidence is sparse with regard to human studies assessing cavernosal tissue before and after treatment with PDE5i. In a study by Schwartz et al, ${ }^{17}$ sildenafil preserved intracorporeal smooth muscle after radical retropubic prostatectomy; the effect of sildenafil on intracorporeal smooth muscle content of post-RP patients was evaluated. Previously potent volunteers $(\mathrm{n}=21)$ received 50 or $100 \mathrm{mg}$ of sildenafil, respectively, every other night for 6 months starting on the day of catheter removal. Cavernosal biopsy was performed under local anesthesia before the RP procedure and after 6 months had elapsed. In the $100 \mathrm{mg}$ group there was a statistically significant increase in mean smooth muscle after surgery $(42.8 \%$ vs $56.9 \%, P<0.05)$ versus no statistically significant change in mean smooth muscle in the $50 \mathrm{mg}$ group ( $51.5 \%$ vs $52.7 \%$ ). The major limitation of this study was the lack of a placebo group and whether this group would have experienced a return of potency. ${ }^{9}$

In general, PDE5i, eg, sildenafil, are often the first-line therapy for patients postprostatectomy. A comprehensive meta-analysis by Montrosi and McCullough ${ }^{18}$ looked at the role of PDE5i therapy in post-RP patients. The overall response rate to therapy was found to be $35 \%$ (95\% CI [confidence interval]: $24 \%-48 \%$ ). This data included patients who received different degrees of nerve sparing (NS) during surgery. It was concluded that NS is a very important factor in determining response rate to PDE5i (NSRP [nerve-sparing radical prostatectomy] ranging from $35 \%-75 \%$ vs non-NS ranging from $0 \%-15 \%$ ); however, not all studies included in the meta-analysis commented on the degree of NS. Another limitation was the lack of a standard measure of EF used by all the studies. ${ }^{3}$

A prospective, two-center, double-blind, parallel group, placebo-controlled randomized controlled trial (RCT) with 76 patients looked at the efficacy of nightly doses of sildenafil in postbilateral nerve-sparing radical prostatectomy (BNSRP) patients. Three groups were compared in this study: sildenafil $50 \mathrm{mg}$, sildenafil $100 \mathrm{mg}$, and placebo. The patients were
Table 3 Contraindications of phosphodiesterase inhibitors

\begin{tabular}{lll}
\hline Sildenafil & Vardenafil & Tadalafil \\
\hline $\begin{array}{l}\text { Organic nitrates } \\
\text { (regular or }\end{array}$ & Nitrates and NO & Organic nitrates \\
(nitric oxide) donors & (regular or intermittent \\
& (regular or intermittent & use), $\alpha$-blockers other \\
& use), $\alpha$-blockers & than 0.4 mg tamsulosin \\
\hline
\end{tabular}

Note: Data from. ${ }^{14}$

administered the drugs on a nightly basis for a total of 36 weeks followed by an 8-week washout period without any erectogenic aid. The first dose was given 4 weeks after surgery. The aim was to compare normalization of spontaneous EF by looking at differences in IIEF scores between the three groups. Normalization occurred in only $4 \%$ of the placebo groups ( 1 in 25 patients) versus $27 \%$ (14 in 51 patients, $P=0.0156$ ) in the sildenafil group. Therefore, it was concluded that surgery alone is inferior to surgery plus rehabilitation (which includes a PDE5i). A limitation of this study was the relatively low number of patients enrolled. A dose-dependent improvement in nocturnal penile tumescence and rigidity using the Rigiscan device (Timm Medical Technologies, Inc., Eden Prairie, MN, USA; a device that measures penile tumescence and rigidity continuously) was noted in a subanalysis of the study. ${ }^{19}$

The largest randomized, placebo-controlled clinical trial ${ }^{20}$ of PDE $5 \mathrm{i}$ in post-RP ED recruited 628 patients post-BNSRP with normal preoperative EF. The three groups compared were on-demand vardenafil, nightly vardenafil, and placebo. This study did not show any significant differences in improving EF and sexual intercourse completion rates between the treatment groups and placebo after the 8-week washout period. Similarly, in the open-label phase of this trial, no advantage of the treatment arm over placebo was shown. ${ }^{9}$ Both studies show conflicting results with neither addressing long-term return of function. ${ }^{18,20}$

There are no approved guidelines on the best approach of PDE5i therapy, nor is there evidence to support one particular program over another. ${ }^{9}$ In a study by Bannowsky et al, ${ }^{21}$ 23 patients with preserved nocturnal erections were treated with nightly doses of sildenafil ( $25 \mathrm{mg}$ per day for 52 weeks) and then compared with a control group $(\mathrm{n}=18)$ who did not experience nocturnal erections (documented by use of the Rigiscan device). In the sildenafil group, $47 \%$ of patients achieved and maintained a penile erection sufficient for vaginal intercourse, compared with $28 \%$ of controls. On-demand, additional doses (50-100 mg) of sildenafil were provided, and the baseline potency went up to $86 \%$ in the sildenafil group compared with $66 \%$ in the control one. The authors concluded that the selection of patients for 
sildenafil should be based only on preserved nocturnal erections post-RP. ${ }^{9}$

Avanafil, a recently released PDE5i, has been found particularly effective in treating ED in post-nerve-sparing RP and diabetic patients. It has successfully treated patients who had previously undergone failed therapy with other PDE5i drugs (sildenafil, tadalafil, vardenafil). ${ }^{22,23}$

Several studies have been carried out reporting the effectiveness of this new therapy, the most notable of which was by Mulhall et al. In this double-blind, parallel study, 298 post-RP ED patients were randomized to placebo or avanafil at 100 and $200 \mathrm{mg}$. A positive, statistically significant increase in IIEF-EF scores was recorded in those patients under both doses of avanafil (3.6 at $100 \mathrm{mg}, 5.2$ at $200 \mathrm{mg}$ ) compared with the placebo group ( 0.1$)$ by the end of the 12-week treatment phase of the study $(P<0.01)$. These beneficial results were maintained at three primary co-end points, throughout measuring the IIEF EF, and were observed in secondary end points, measuring other IIEF domains (orgasmic function, sexual desire, intercourse, and overall satisfaction). Many participants reported improvements using avanafil within 15-30 minutes, an advantageous early onset characteristic caused by the rapid rate of absorption of this drug. It is also noteworthy to report that $71.5 \%$ of participants had severe $\mathrm{ED}$ at baseline, before treatment initiation (mean overall IIEF-EF domain score was 9.2). ${ }^{23}$

\section{Vacuum Erection devices (VEDs)}

The vacuum erection device (VED) functions by drawing blood into the corporal bodies through the use of a manually created negative pressure gradient. A constriction ring can then be applied to the base of the penis, thereby preventing venous return and sustaining an erection. ${ }^{2}$ Although an erection that is sufficient for intercourse may be created, it is questionable whether this erection will provide sufficient oxygen saturation of the corporal tissue to prevent future fibrosis. Many clinicians dismiss this since it has been shown that an erection created by a VED consists of $5 \%$ arterial blood and $42 \%$ venous blood, and has a $\mathrm{SaO}_{2}$ of $76 \%$. This is comparable to the $\mathrm{SaO}_{2}$ of PGE-1-induced erections of $78.5 \%$. These two methods should be considered equal in terms of oxygenation potential; this needs to be communicated to patients to aid in decision making with regard to management. Evidence from a small pilot study suggests that early (1 month postsurgery) VED therapy after nerve-sparing RP both improves EF and prevents loss of penile length at 3 and 6 months. This is in comparison with a group that commenced the VED therapy 6 months postoperatively. At the last follow-up (on average
9.5 months post-RP), there was no significant difference in EF and penile length between the two groups. ${ }^{5}$

It should also be noted that VED is more cost effective than other therapy options owing to the absence of a marginal cost of usage and its long-term viability, with it having an approximate life span of five years. In addition, VED has the ability to achieve for some individuals an erection sufficient for sexual function almost immediately, with minimal side effects. ${ }^{3}$ Furthermore, Vasdev et al exhibited the low cost associated with VED (£228) compared with an alprostadil injection (£2589) treatment over a 5-year period. ${ }^{24}$

Evidence has suggested improvements in both sexual function and penile length when using VEDs. There is little justification for using VED as a monotherapy for post-RP patients. Evidence for VED as a complementary therapy to PDE5i is promising, particularly when used prior to intercourse. VED offers a noninvasive and cost-effective modality for achieving an erection and should be considered when discussing treatment options with patients. ${ }^{2}$

\section{Intraurethral suppository - Alprostadil}

Alprostadil $\left(\mathrm{MUSE}^{\circledR}\right)$, a PGE1 analog administered as an intraurethral suppository, is thought to increase corporal oxygenation by promoting blood flow. Furthermore, PGE1 is deficient in penile tissues after RP-induced damage, and this also serves as a rationale for using alprostadil. In post-RP patients experiencing ED, alprostadil has demonstrated benefits in terms of intercourse success rates, and thus improvements in IIEF scores. However, patients have reported discomfort and pain associated with treatment. Therefore, noncompliance may be a factor in determining the cost-effectiveness of this therapy. ${ }^{2}$

In a prospective randomized penile rehabilitation trial, McCullough et al compared the effectiveness of nightly intraurethral alprostadil versus $50 \mathrm{mg}$ oral sildenafil citrate after NSRP. No statistically significant differences in the IIEF erectile function domain and intercourse success rates were observed between the two groups. The authors concluded that the return of EF with nightly sildenafil citrate and subtherapeutic intraurethral alprostadil appears to be similar within the first year after surgery. ${ }^{25}$

\section{Intracavernosal injections}

Intracavernosal injections (ICIs) are among the most established methods of producing an erection in any patient with ED. Improved knowledge in the physiologic mechanisms behind erections has led to a change from alprostadil-based ICIs to a TriMix (papaverine, phentolamine, and PGE1). 
Evidence suggests that for nonresponders to PDE5is, ICIs are effective in restoring EF. It has potential as a therapeutic strategy in nonresponders; however, psychosexual concerns associated with self-administrated penile injections should be taken into consideration when decision-making with patients. $^{2}$

Alprostadil-based ICIs often cause penile pain that may lead to high discontinuation rates. Therefore, it would be wise to reserve ICI treatment for patients in whom PDE5i are considered ineffective. However, there is emerging evidence that TriMix is associated with less pain (both after injection and during erections) than alprostadil-based ICIs. ${ }^{13}$

\section{Penile prosthesis implantation}

This invasive surgical approach is limited for use in patients with end-stage ED following RP. ICSM committee experts concluded that penile prostheses should be indicated as a third-line treatment. ${ }^{26}$ Results from a large epidemiological study has highlighted that penile prostheses are scarcely requested after prostate cancer treatment. ${ }^{27}$ This is not due to a poor outcome after implant treatment as the literature has shown quite the opposite. Penile implants have been associated with technical feasibility, safety, high efficacy as an ED treatment with higher treatment satisfaction compared with PDE5i or ICI in both patients and partners.

In a study by Megas et al, the outcome of penile prosthesis surgery in comparison with PDE5i in men with ED postNSRP as an early penile intervention therapy was assessed. A total of 153 patients fulfilled the inclusion criteria of the study, and 69 (45\%) presented with post-radical retropubic prostatectomy erectile dysfunction 6 months after surgery. Fifty four of these patients were disease-free and were split into two groups: Tadalafil three times per week or penile prosthesis implantation. All patients were evaluated using the IIEF questionnaire preoperatively and at 6, 12, and 24 months postoperatively. In both groups, there was a significant reduction of the IIEF score preoperative values to the first measurement after surgery. However, the degree of change of IIEF scores from immediately after surgery to 2 years was greater in the penile prosthesis group than the tadalafil group (20.4 \pm 1.3 vs $8.1 \pm 2.4, P<0.001)$. Penile prosthesis was superior to oral treatment in terms of the following parameters: frequency, firmness, penetration ability, maintenance, and erection confidence. The authors concluded that the concept of early penile prosthesis intervention should be considered for all patients who suffer from post-RP ED. Limitations include a relatively small cohort of patients and a lack of discussion about the potential cost of surgery in comparison with that of pharmacological treatment. ${ }^{28}$

\section{Discontinuation of treatment}

It is important to note that significant rates of discontinuation have been exhibited by patients who have undertaken each of the different modes of therapies displayed above. Discontinuation occurs from a multitude of causes that differ depending on the treatment taken; many studies have probed into these and estimated the corresponding rates of discontinuation for each therapy using various regimens (Table 4).

Table 4 Rates and reasons for discontinuation for different treatment modalities

\begin{tabular}{|c|c|c|}
\hline Treatment & Incidences of discontinuation & Reasons for discontinuation \\
\hline $\begin{array}{l}\text { Phosphodiesterase type } 5 \\
\text { inhibitor-(PDE5i) }\end{array}$ & $\begin{array}{l}\text { An overall } 72.6 \% \text { discontinuation rate found } \\
\text { at an I8-month follow-up for patients using } \\
\text { both daily PDE5i and as needed PDE5i therapy }\end{array}$ & $\begin{array}{l}\text { Effect below expectations } \\
\text { Loss of interest in sex in either partner or patients } \\
\text { High cost } \\
\text { Side effects of treatment }\end{array}$ \\
\hline $\begin{array}{l}\text { Vacuum Erection Devices } \\
\text { (VEDs) })^{30}\end{array}$ & $\begin{array}{l}20 \%(28 / I \mid 3) \text { discontinuation after I year of VED } \\
\text { use. This increased to } 38 \%(43 / I / 3) \text { after } \\
5 \text { years of treatment }\end{array}$ & $\begin{array}{l}\text { Loss of interest in sex } \\
\text { Urinary incontinence } \\
\text { Loss of libido } \\
\text { Cardiovascular and CNS effects (seen only in the 5-year } \\
\text { discontinuers) }\end{array}$ \\
\hline Intraurethral Suppository ${ }^{3 \mid}$ & $\begin{array}{l}32 \%(18 / 56) \text { discontinuation rate in patients } \\
\text { treated with } \text { MUSE }^{\circledR} \text { before the end of a 9-month } \\
\text { treatment period }\end{array}$ & $\begin{array}{l}\text { Lack of efficacy/insufficient erections } \\
\text { Reduced sexual interest } \\
\text { Adverse effects of the medication (urethral burning or pain) }\end{array}$ \\
\hline $\begin{array}{l}\text { Intracavernosal Injections } \\
(\mathrm{ICls})^{32}\end{array}$ & $\begin{array}{l}52 \%(53 / I 02) \text { of patients discontinued } \mathrm{ICl} \text { therapy } \\
\text { after a mean use of } 14.5 \text { months }\end{array}$ & $\begin{array}{l}\text { Insufficient erections } \\
\text { Preference for oral therapy } \\
\text { Fear of injections } \\
\text { Troublesome procedure } \\
\text { Priapism } \\
\text { Return of natural erection }\end{array}$ \\
\hline
\end{tabular}




\section{Psychological and sexual counseling}

The ICSM committee recommends that clinicians should communicate the essential elements of the pathophysiology of post-RP $\mathrm{ED}^{1,2}$ and that penile rehabilitation may have potential benefits for the patient. ${ }^{13}$ In a small prospective study by Titta et al, a small cohort of patients who completed the IIEF one month after non-NSRP were shown how to use ICI. The patients were later randomized to either ICI treatment alone or a group who received PGE1-ICI therapy and sexual counseling for 18 consecutive months. The study showed that men who were in the latter group reported the best quality in all IIEF domains, the lowest discontinuation rate, and the highest degree of couple satisfaction compared with the men who did not receive counseling in combination with the ICI therapy. The counseling reduced the number of patients reporting lack of sexual spontaneity, dissatisfaction, and fear of needles. ${ }^{13,33}$ This highlights the major importance of counseling as an effective contribution to ameliorating treatment efficacy as well as patient compliance, and as such lowering the discontinuation rates mentioned previously. ${ }^{33}$

\section{Practical therapeutic approaches}

The UK has yet to devise a national strategy for treatment of post-RP ED, taking into consideration the literature, licensed treatments, and cost-effectiveness. This particular approach is taken from the Baylor College of Medicine. Their protocol revolves around the use of PDE5i daily at a low dose, with the regimen of treatment aptly starting before the surgery and continuing shortly after. ${ }^{3}$ Furthermore, this protocol in its use of PDE5i has instructed doses and combinations that recognize results found in the literature of proven efficacy. The oral route of treatment in the early portion of the study considers patient convenience and comfort.

Moskovic et $\mathrm{al}^{34}$ instructs patients to take $25 \mathrm{mg}$ of sildenafil every night in addition to $250 \mu \mathrm{g}$ alprostadil urethral suppositories three times per week. The treatment regimen begins up to 1 week prior to surgery. Patients are instructed to restart $25 \mathrm{mg}$ of sildenafil nightly 3 days post-RP and add $250 \mu \mathrm{g}$ alprostadil suppositories three times per week once the catheter has been removed. One month after RP, the patients are seen in clinic, where the response to therapy is assessed. Patients are encouraged to engage in sexual activity if medically cleared. Alprostadil is dose-titrated if indicated, side effects are established, the importance of compliance is reviewed, and patients are asked about spontaneous EF. Finally, all patients are introduced to VED usage. Patients are instructed to use a VED at least 10 minutes a day. Three months after RP, ICIs are introduced in the EF preservation program for patients who are not responding to the combination of sildenafil, MUSE and VED. The patients are instructed to self-inject a TriMix 3 days per week in addition to the nightly $25 \mathrm{mg}$ of sildenafil and the daily VED therapy. These particular patients are seen on a monthly basis to reestablish whether a combination therapy of sildenafil, VEDs, and alprostadil suppositories may be reintroduced (Figure 1).

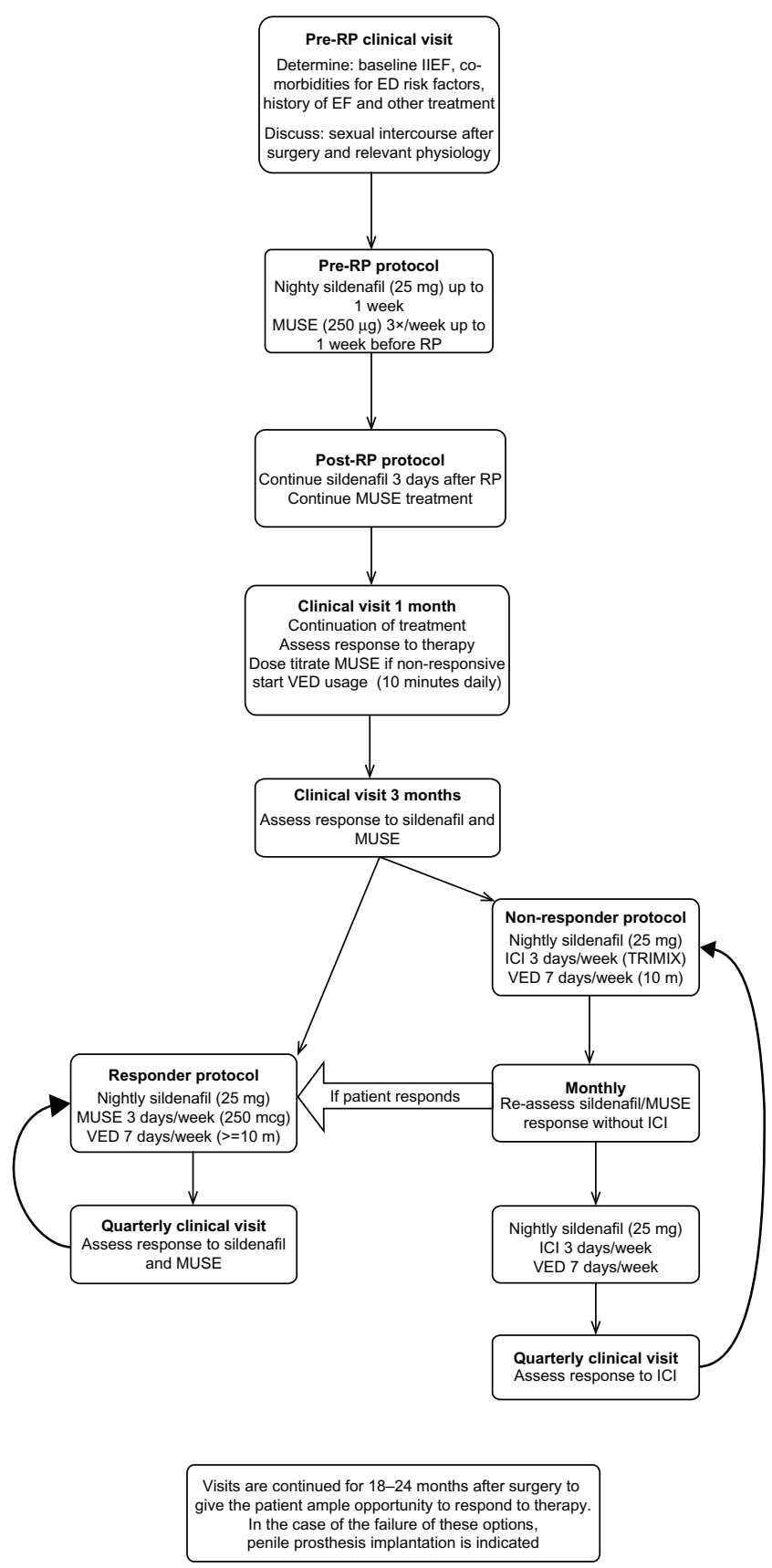

Figure I A suggested approach to management of erectile dysfunction in the context of a radical prostatectomy. 
All clinical visits also involved the following procedures:

- Reviewing the importance of compliance

- Determining side effects

- Inquiring about spontaneous EF

- Encouraging continuation of erectile preservation (educating the patient on the importance of compliance to the protocol and to the dosing regimen).

\section{Future treatments Dietary}

A number of trials (including two randomized, placebocontrolled trials) have looked into the combination of L-arginine and Pycnogenol (extract of the French pine tree Pinus pinaster) with promising results. L-arginine has been shown to increase levels of eNOS and Pycnogenol, an antioxidant that stimulates the conversion of L-arginine into $\mathrm{NO}$ via eNOS. The trials demonstrated increased patient-reported EF during 1 month of supplementation without the use of on-demand therapies (eg, PDE5i). The major limitation is that the trials were designed for non-radical prostatectomies and therefore more appropriately designed randomized controlled trials involving patient post-RP are required. ${ }^{4}$

Care should be taken when discussing dietary supplements, as there have been a number of commercially available supplements promoted as a means of natural enhancement. The lack of efficacy studies should be highlighted to the patient. ${ }^{4}$

\section{Gene therapy}

Despite the numerous aforementioned options of management that can be used in treating ED post-RP and their relatively high success rates, some patients do not have a successful outcome. As such, the feasibility of gene therapy has been researched in the past ten years. Its functionality centers on the operation of three physiological functions whose enhancement restores erectile activity: ${ }^{35}$

- Enhancing NO production or NO-medicated signaling pathways (restoration of endogenous NO synthesis and/ or enhancement of the NO-related cascade in the penis). This can take place through the injection of recombinant adenovirus containing the eNOS gene into the corpus cavernosum, resulting in increased eNOS transgene expression and cGMP levels. This has also been found to enhance intracavernosal pressure (ICP) increase in response to cavernous nerve stimulation. In addition to eNOS, gene delivery of other nitric oxide synthase (NOS) subtypes such as nNOS (neuronal NOS) and iNOS into the penis also improves EF.
- Enhancing growth factor-mediated nerve regeneration. This process can be mediated through increasing the levels of numerous growth factors, one of which is the promising Neurotrophin-3 (NT3). NT3 was found to increase fiber growth in male rat major pelvic ganglia cultures more than other growth factors. This result was followed up with an experiment that compared HSV (Herpes simplex virus) vector mediated NT3 versus HSV vector expressing Beta galactosidase postinjection into cavernous nerve sheaths. Data measurements collected four weeks later suggest that NT3 might assist regeneration/repair/survival and increased nNOS expression in pelvic ganglion neurons to restore EF in diabetic rats. This was supported with the fact that the mean number of NOS positive neurons per section in the NT3 group was much greater than in the $\beta$ galactosidase one and the former group achieved maximal ICP. Similar beneficial results have been displayed with other growth factors like GDNF (Glial cell line-derived neurotrophic factor), NTN (neurturin), BDNF (brain derived neurotrophic factor), IGF1 (insulin-like growth factor 1), and VEGF (vascular endothelial growth factor).

- Enhancing potassium ion channel activity and conductance in the cavernous smooth muscle. Potassium ion channels stabilize the membrane potential and reduce the excitability of nerves and muscle cells, including smooth muscle cells in the penis.

Penile corporeal muscle relaxation occurs with decrease in calcium levels due to hyperpolarization of smooth muscle. This takes place because of membrane potential depolarization, an increase in cystolic calcium ion levels, and/or $\mathrm{NO}$ / cGMP-mediated mechanisms that activate calcium-activated potassium channels. Studies ${ }^{36,37}$ have revolved around the gene transfer of naked hSlo cDNA that encodes the human BK channel (potassium channels characterized by their large conductance of potassium ions $\left[\mathrm{K}^{+}\right]$through cell membranes) $\alpha$-subunit to intracavernosum. Halo cDNA is inserted into a mammalian plasmid, after which its expression is driven by a promoter. The plasmid is designed to replicate the inserted DNA sequence. The plasmid with its desired DNA sequence enters the nucleus of the host cell and transcribes the desired mRNA strand, producing functional BK channel proteins. Significant elevation of ICP in response to cavernous nerve stimulation was also noticed in aged or diabetic rats that had plasmid-containing Halo DNA injected intracavernously.

Great promise has been shown with these approaches and their potential has been exhibited on rat models; however, concern remains with the safety of gene therapy and its 
clinical translation to patients. This is best resembled with the use of viral delivery vehicles to transfer the genes. Viruses have acquired efficient methods to deliver their own genetic material to cells and can be readily produced and purified for in vivo gene transfer in contrast to nonviral methods that have production limited to sufficient quantities of DNA for transduction. However, this method incorporates a high level of risk owing to endogenous viral recombination, cancer development, and immunological reactions. ${ }^{38}$

\section{Conclusion}

ED is a reality for many men post-RP. One significant obstacle is the lack of a standardized, objective, universal definition to accurately define baseline EF and postoperative ED. This makes it challenging to tailor treatment, manage expectations, and also monitor progress in patients who suffer from post-RP ED. Nevertheless, treatment remains undoubtedly superior to leaving the tissue without intervention.

Treatment and recovery are possible, but the process of rehabilitation should be initiated as early as catheter removal or during the first month post-RP. ${ }^{13}$ There is evidence supporting this notion and suggesting benefits in early postoperative treatment with PDE5i as this may certainly lead to positive long-term results in terms of recovery of EF. Patient expectations and wishes should be discussed; this includes achieving a good understanding of baseline EF. On-demand PDE5i (sildenafil, tadalafil, and vardenafil) may prove useful in patients who have undergone NSRP (there are no definitive conclusions to suggest greater, long-term benefits of daily PDE5i use versus an on-demand use in post-RP patients). ${ }^{2}$ Although the rationale in using a PDE5i in the rehabilitation process may seem reasonable, further research is needed to optimize prognoses of patients. This includes deciding when to start, the dosage regimen prescribed, total period of treatment, suitability of patients, and which drug is best to use. ${ }^{9}$ Although numerous animal studies have suggested that PDE5i can prevent smooth muscle apoptosis and fibrosis, this is yet to be established in human trials. ICIs should mainly be considered in patients nonresponsive to PDE5i in combination with VEDs and alprostadil suppository.

Although penile pain associated with self-administered injections may diminish over time, TriMix injections may lead to better compliance, as they are associated with less pain. Psychological and sexual counseling has shown additional improvements for rehabilitation and treatment strategies of post-RP ED; it is recommended by both the ICSM and published literature. Finally, in a reserved group of patients with evidence of end-stage ED, penile prosthesis should also be a point of discussion, especially when less invasive treatment has failed.

\section{Disclosure}

The authors declare no conflicts of interest.

\section{References}

1. Salonia A, Burnett AL, Graefen M, et al. Prevention and management of postprostatectomy sexual dysfunctions. Part 1: choosing the right patient at the right time for the right surgery. Eur Urol. 2012;62(2): 261-272.

2. Heidenreich A, Bellmunt J, Bolla M, et al. EAU Guidelines on Prostate Cancer. Part 1: screening, diagnosis, and treatment of clinically localised disease. Eur Urol. 2011;59(1):61-71.

3. Moskovic DJ, Miles BJ, Lipshultz LI, Khera M. Emerging concepts in erectile preservation following radical prostatectomy: a guide for clinicians. Int J Impot Res. 2011;23(5):181-192.

4. Jamal JE, Engel JD. Management of post-prostatectomy erectile dysfunction. Can J Urol. 2011;18(3):5726-5730.

5. Park DL, Aron M, Rewcastle JC, Boyd SD, Gill IS. A model for managing erectile dysfunction following prostate cancer treatment. Curr Opin Urol. 2013;23(2):129-134.

6. Montorsi F, Briganti A, Salonia A, Rigatti P, Burnett AL. Current and future strategies for preventing and managing erectile dysfunction following radical prostatectomy. Eur Urol. 2004;45(2):123-133.

7. Salonia A, Castagna G, Capogrosso P, Castiglione F, Briganti A, Montorsi F. Prevention and management of post prostatectomy erectile dysfunction. Transl Androl Urol. September 10, 2013. doi: 10.3978/j. issn.2223-4683.2013.09.10

8. Förstermann U, Sessa WC. Nitric oxide synthases: regulation and function. Eur Heart J. 2012;33(7):829-837.

9. Hatzimouratidis K, Burnett AL, Hatzichristou D, McCullough AR, Montorsi F, Mulhall JP. Phosphodiesterase type 5 inhibitors in postprostatectomy erectile dysfunction: a critical analysis of the basic science rationale and clinical application. Eur Urol. 2009;55(2): 334-347.

10. Mulhall JP, Bella AJ, Briganti A, McCullough A, Brock G. Erectile function rehabilitation in the radical prostatectomy patient. $J$ Sex Med. 2010;7(4, pt 2):1687-1698.

11. Sato Y, Tanda H, Nakajima H, et al. Dissociation between patients and their partners in expectations for sexual life after radical prostatectomy. Int J Urol. 2013;20(3):322-328.

12. Kava BR. Advances in the management of post-radical prostatectomy erectile dysfunction: treatment strategies when PDE-5 inhibitors don't work. Rev Urol. 2005;7(Suppl 2):S39-S50.

13. Salonia A, Burnett AL, Graefen M, et al. Prevention and management of postprostatectomy sexual dysfunctions part 2: recovery and preservation of erectile function, sexual desire, and orgasmic function. Eur Urol. 2012;62(2):273-286.

14. Kloner RA. Cardiovascular effects of the 3 phosphodiesterase-5 inhibitors approved for the treatment of erectile dysfunction. Circulation. 2004;110(19):3149-3155.

15. Wright PJ. Comparison of phosphodiesterase type 5 (PDE5) inhibitors. Int J Clin Pract. 2006;60(8):967-975.

16. Behr-Roussel D, Gorny D, Mevel K, et al. Chronic sildenafil improves erectile function and endothelium-dependent cavernosal relaxations in rats: lack of tachyphylaxis. Eur Urol. 2005;47(1):87-91.

17. Schwartz EJ, Wong P, Graydon RJ. Sildenafil preserves intracorporeal smooth muscle after radical retropubic prostatectomy. $J$ Urol. 2004;171(2, pt 1):771-774.

18. Montorsi F, McCullough A. Efficacy of Sildenafil Citrate in Men with Erectile Dysfunction Following Radical Prostatectomy: A Systematic Review of Clinical Data. J Sexual Medicine. $2005 ; 2(5): 658-667$. 
19. Padma-Nathan H, McCullough AR, Levine LA, et al. Randomized, double-blind, placebo-controlled study of postoperative nightly sildenafil citrate for the prevention of erectile dysfunction after bilateral nervesparing radical prostatectomy. Int J Impot Res. 2008;20(5):479-486.

20 Montorsi F, Brock G, Lee J, Shapiro J, Van Poppel H, Graefen M, et al. Effect of Nightly versus On-Demand Vardenafil on Recovery of Erectile Function in Men Following Bilateral Nerve-Sparing Radical Prostatectomy. European Urology. 2008;54(4):924-931.

21. Bannowsky A, Schulze H, van der Horst C, Hautmann S, Jünemann K. Recovery of erectile function after nerve-sparing radical prostatectomy: improvement with nightly low-dose sildenafil. BJU Int. 2008;101(10):1279-1283.

22. Kyle JA, Brown DA, Hill JK. Avanafil for erectile dysfunction. Ann Pharmacother. 2013;47(10):1312-1320.

23. Mulhall JP, Burnett AL, Wang R, et al. A phase 3, placebo controlled study of the safety and efficacy of avanafil for the treatment of erectile dysfunction after nerve sparing radical prostatectomy. $J$ Urol. 2013;189(6):2229-2236.

24. Vasdev N, Hoyland K, Adshead JM. Is it still clinically and economically viable in the UK to prescribe vacuum erection devices for patients with erectile dysfunction after radical prostatectomy? BJU Int. 2014;113(3):356-357.

25. McCulloughAR, Hellstrom WG, Wang R, Lepor H, Wagner KR, Engel JD. Recovery of erectile function after nerve sparing radical prostatectomy and penile rehabilitation with nightly intraurethral alprostadil versus sildenafil citrate. J Urol. 2010;183(6):2451-2456.

26. Montorsi F, Adaikan G, Becher E, et al. Summary of the recommendations on sexual dysfunctions in men. Jf Sex Med. 2010;7(11): 3572-3588.

27. Tal R, Jacks LM, Elkin E, et al. Penile implant utilization following treatment for prostate cancer: analysis of the SEER-Medicare database. J Sex Med. 2011;8:1797-1804.

28. Megas G, Papadopoulos G, Stathouros G, Moschonas D, Gkialas I, Ntoumas K. Comparison of efficacy and satisfaction profile, between penile prosthesis implantation and oral PDE5 inhibitor tadalafil therapy, in men with nerve-sparing radical prostatectomy erectile dysfunction. BJU Int. 2013;112(2):E169-E176.
29. Salonia A, Gallina A, Zanni G, et al. Acceptance of and discontinuation rate from erectile dysfunction oral treatment in patients following bilateral nerve-sparing radical prostatectomy. Eur Urol. 2008;53(3): 564-570.

30. Raina R, Pahlajani G, Agarwal A, Jones S, Zippe C. Long-term potency after early use of a vacuum erection device following radical prostatectomy. BJU Int. 2010;106(11):1719-1722.

31. Raina R, Pahlajani G, Agarwal A, Zippe CD. The early use of transurethral alprostadil after radical prostatectomy potentially facilitates an earlier return of erectile function and successful sexual activity. BJU Int. 2007;100(6):1317-1321.

32. Raina R, Lakin MM, Thukral M et al. Long-term efficacy and compliance of intracorporeal (IC) injection for erectile dysfunction following radical prostatectomy: SHIM (IIEF-5) analysis. Int J Impot Res. 2003;15:318-322.

33. Titta M, Tavolini IM, Dal Moro F, Cisternino A, Bassi P. Sexual counseling improved erectile rehabilitation after non-nerve-sparing radical retropubic prostatectomy or cystectomy - results of a randomized prospective study. J Sex Med. 2006;3(2):267-273.

34. Moskovic DJ, Mohamed O, Sathyamoorthy K, et al. The female factor: predicting compliance with a post-prostatectomy erectile preservation program. J Sex Med. 2010;7(11):3659-3665.

35. Yoshimura N, Kato R, Chancellor MB, Nelson JB, Glorioso JC. Gene therapy as future treatment of erectile dysfunction. Expert Opin Biol Ther. 2010;10(9):1305-1314.

36. Christ GJ, Rehman J, Day N, Salkoff L, Valcic M, Melman A, et al. Intracorporal injection of hSlo cDNA in rats produces physiologically relevant alterations in penile function. Am J Physiol. 1998;275(2 Pt 2): H600-H608.

37. Melman A, Zhao W, Davies KP, Bakal R, Christ GJ. The successful long-term treatment of age related erectile dysfunction with hSlo cDNA in rats in vivo. J Urol. 2003;170(1):285-290.

38. Gur S, Kadowitz PJ, Hellstrom WJG. A review of current progress in gene and stem cell therapy for erectile dysfunction. Expert Opin Biol Ther. 2008;8(10):1521-1538. 


\section{Supplementary materials}

Table SI Patient questionnaire based on International Index of Erectile Function (IIEF) and its clinical application

\author{
INTERNATIONAL INDEX \\ OF ERECTILE FUNCTION (IIEF)
}

HOSPITAL NUMBER (IF KNOWN)
NAME
DATE OF BIRTH $~$
ADDRESS

TELEPHONE

Patient Questionnaire

Please check one box only

\section{Over the past 4 weeks}

How often were you able to get an erection during sexual activity?

Q2

When you had erections with sexual stimulation, how often were your erections hard enough for penetration?

Q3

Q4

Q5
When you attempted intercourse, how often were you able to penetrate (enter) your partner?

During sexual intercourse, how often were you able to maintain your erection after you had penetrated (entered) your partner?

During sexual intercourse, how difficult was it to maintain your erection to completion of intercourse?

How many times have you attempted sexual intercourse?
0 No sexual activity

I Almost never or never

$2 \mathrm{~A}$ few times (less than half the time)

3 Sometimes (about half the time)

4 Most times (more than half the time)

5 Almost always or always

0 No sexual activity

I Almost never or never

$2 \mathrm{~A}$ few times (less than half the time)

3 Sometimes (about half the time)

4 Most times (more than half the time)

5 Almost always or always

0 Did not attempt intercourse

I Almost never or never

$2 \mathrm{~A}$ few times (less than half the time)

3 Sometimes (about half the time)

4 Most times (more than half the time)

5 Almost always or always

0 Did not attempt intercourse

I Almost never or never

$2 \mathrm{~A}$ few times (less than half the time)

3 Sometimes (about half the time)

4 Most times (more than half the time)

5 Almost always or always

0 Did not attempt intercourse

I Extremely difficult

2 Very difficult

3 Difficult

4 Slightly difficult

5 Not difficult

0 No attempts

I One to two attempts

2 Three to four attempts

3 Five to six attempts

4 Seven to ten attempts

5 Eleven or more attempts 
Table SI (Continued)

\begin{tabular}{|c|c|c|}
\hline \multirow[t]{6}{*}{ Q7 } & When you attempted sexual intercourse, how often was it & 0 Did not attempt intercourse \\
\hline & satisfactory for you? & I Almost never or never \\
\hline & & 2 A few times (less than half the time) \\
\hline & & 3 Sometimes (about half the time) \\
\hline & & 4 Most times (more than half the time) \\
\hline & & 5 Almost always or always \\
\hline \multirow[t]{6}{*}{ Q8 } & How much have you enjoyed sexual intercourse? & 0 No intercourse \\
\hline & & I No enjoyment at all \\
\hline & & 2 Not very enjoyable \\
\hline & & 3 Fairly enjoyable \\
\hline & & 4 Highly enjoyable \\
\hline & & 5 Very highly enjoyable \\
\hline \multirow[t]{6}{*}{ Q9 } & When you had sexual stimulation or intercourse, how often did & 0 No sexual stimulation or intercourse \\
\hline & you ejaculate? & I Almost never or never \\
\hline & & 2 A few times (less than half the time) \\
\hline & & 3 Sometimes (about half the time) \\
\hline & & 4 Most times (more than half the time) \\
\hline & & 5 Almost always or always \\
\hline \multirow[t]{5}{*}{ Q10 } & When you had sexual stimulation or intercourse, how often did & I Almost never or never \\
\hline & you have the feeling of orgasm or climax? & $2 \mathrm{~A}$ few times (less than half the time) \\
\hline & & 3 Sometimes (about half the time) \\
\hline & & 4 Most times (more than half the time) \\
\hline & & 5 Almost always or always \\
\hline \multirow[t]{5}{*}{ QII } & How often have you felt sexual desire? & I Almost never or never \\
\hline & & 2 A few times (less than half the time) \\
\hline & & 3 Sometimes [about half the time) \\
\hline & & 4 Most times (more than half the time) \\
\hline & & 5 Almost always or always \\
\hline \multirow[t]{5}{*}{ Q12 } & How would you rate your level of sexual desire? & I Very low or none at all \\
\hline & & 2 Low \\
\hline & & 3 Moderate \\
\hline & & 4 High \\
\hline & & 5 Very high \\
\hline \multirow[t]{5}{*}{ Q13 } & How satisfied have you been with your overall sex life? & I Very dissatisfied \\
\hline & & 2 Moderately dissatisfied \\
\hline & & 3 Equally satisfied and dissatisfied \\
\hline & & 4 Moderately satisfied \\
\hline & & 5 Very satisfied \\
\hline \multirow[t]{5}{*}{ Q14 } & How satisfied have you been with your sexual relationship with & I Very dissatisfied \\
\hline & your partner? & 2 Moderately dissatisfied \\
\hline & & 3 Equally satisfied and dissatisfied \\
\hline & & 4 Moderately satisfied \\
\hline & & 5 Very satisfied \\
\hline \multirow[t]{5}{*}{ Q15 } & How do you rate your confidence that you could get and keep & I Very low \\
\hline & an erection? & 2 Low \\
\hline & & 3 Moderate \\
\hline & & 4 High \\
\hline & & 5 Very high \\
\hline
\end{tabular}

\section{INTERNATIONAL INDEX OF ERECTILE FUNCTION (IIEF)}

\section{Guidelines on Clinical Application of IIEF Patient Questionnaire}

\section{Background}

The I5-question International Index of Erectile Function (IIEF) Questionnaire is a validated, multidimensional, self-administered investigation that has been found useful in the clinical assessment of erectile dysfunction and treatment outcomes in clinical trials. A score of $0-5$ is awarded to each of the 15 questions that examine the 4 main domains of male sexual function: erectile function, orgasmic function, sexual desire and intercourse satisfaction. 
In a recent study(I), the IIEF Questionnaire was tested in a series of III men with sexual dysfunction and I09 age-matched, normal volunteers. The following mean scores were recorded:

\begin{tabular}{llll}
\hline Function & Maximum & Mean Scores & \\
\cline { 3 - 4 } Domain & Score Possible & Controls & Patients \\
\hline A. Erectile Function $(\mathrm{Q} \mid, 2,3,4,5,15)$ & 30 & 25.8 & 10.7 \\
B. Orgasmic Function $(\mathrm{Q} 9,10)$ & 10 & 9.8 & 5.3 \\
C. Sexual Desire $(\mathrm{Q}$ I I, I2) & 10 & 7.0 & 6.3 \\
D. Intercourse Satisfaction $(\mathrm{Q} 6,7,8)$ & 15 & 10.6 & 5.5 \\
E. Overall Satisfaction $(\mathrm{Q} \mid 3,14)$ & 10 & 8.6 & 4.4 \\
\hline
\end{tabular}

\section{Clinical Application}

IIEF assessment is limited by the superficial assessment of psychosexual background and the very limited assessment of partner relationship, both important factors in the presentation of male sexual dysfunction. Analysis of the questionnaire should, therefore, be viewed as an adjunct to, rather than a substitute for, a detailed sexual history and examination. The following guidelines may be applied:

I. Patients with low IIEF scores ( $<14$ out of 30 ) in Domain A (Erectile Function) may be considered for a trial course of therapy with Sildenafil unless contraindicated. Specialist referral is indicated if this is unsuccessful.

2. Patients demonstrating primary orgasmic or ejaculatory dysfunction (Domain B) should be referred for specialist investigation.

3. Patients with reduced sexual desire (Domain C) require testing of blood levels of androgen and prolactin.

4. Psychosexual counselling should be considered if low scores are recorded in Domains $D$ and $E$ but there is only a moderately lowered score (14 to 25) in Domain A. 
Table S2 Sexual Health Inventory for Men (SHIM)

\section{SEXUAL HEALTH INVENTORY FOR MEN (SHIM)}

PATIENT NAME:

TODAY'S DATE:

\section{PATIENT INSTRUCTIONS}

Sexual health is an important part of an individual's overall physical and emotional well-being. Erectile dysfunction, also known as impotence, is one type of very common medical condition affecting sexual health. Fortunately, there are many different treatment options for erectile dysfunction. This questionnaire is designed to help you and your doctor identify if you may be experiencing erectile dysfunction. If you are, you may choose to discuss treatment options with your doctor.

Each question has several possible responses. Circle the number of the response that best describes your own situation. Please be sure that you select one and only one response for each question.

\section{OVER THE PAST 6 MONTHS:}

\begin{tabular}{|c|c|c|c|c|c|c|}
\hline \multirow[t]{2}{*}{$\begin{array}{l}\text { I. How do you rate your } \\
\text { confidence that you could } \\
\text { get and keep an erection? }\end{array}$} & & VERY LOW & Low & MODERATE & HIGH & Very High \\
\hline & & I & 2 & 3 & 4 & 5 \\
\hline \multirow{2}{*}{$\begin{array}{l}\text { 2. When you had erections } \\
\text { with sexual stimulation, how } \\
\text { often were your erections } \\
\text { hard enough for penetration } \\
\text { (entering your partner)? }\end{array}$} & $\begin{array}{l}\text { No SeXual } \\
\text { ACtivity }\end{array}$ & $\begin{array}{l}\text { ALmOst NeVER } \\
\text { OR NeVER }\end{array}$ & $\begin{array}{l}\text { A FEW TIMES } \\
\text { (MUCH LESS } \\
\text { THAN HALF } \\
\text { THE TIME) }\end{array}$ & $\begin{array}{l}\text { SOMETIMES } \\
\text { (ABOUT HALF } \\
\text { THE TIME) }\end{array}$ & $\begin{array}{l}\text { MOST TIMES } \\
\text { (MUCH MORE } \\
\text { THAN HALF } \\
\text { THE TIME) }\end{array}$ & $\begin{array}{l}\text { ALMOST } \\
\text { ALWAYS OR } \\
\text { ALWAYS }\end{array}$ \\
\hline & 0 & I & 2 & 3 & 4 & 5 \\
\hline \multirow{2}{*}{$\begin{array}{l}\text { 3. During sexual intercourse, } \\
\text { how often were you able } \\
\text { to maintain your erection } \\
\text { after you had penetrated } \\
\text { (entered) your partner? }\end{array}$} & $\begin{array}{l}\text { DID NOT } \\
\text { ATTEMPT } \\
\text { INTERCOURSE }\end{array}$ & $\begin{array}{l}\text { Almost NeVer } \\
\text { OR NeVER }\end{array}$ & $\begin{array}{l}\text { A FEW TIMES } \\
\text { (MUCH LESS } \\
\text { THAN HALF } \\
\text { THE TIME) }\end{array}$ & $\begin{array}{l}\text { SOMETIMES } \\
\text { (ABOUT HALF } \\
\text { THE TIME) }\end{array}$ & $\begin{array}{l}\text { MOST TIMES } \\
\text { (MUCH MORE } \\
\text { THAN HALF } \\
\text { THE TIME) }\end{array}$ & $\begin{array}{l}\text { ALMOST } \\
\text { ALWAYS OR } \\
\text { ALWAYS }\end{array}$ \\
\hline & 0 & I & 2 & 3 & 4 & 5 \\
\hline \multirow{2}{*}{$\begin{array}{l}\text { 4. During sexual intercourse, } \\
\text { how difficult was it to } \\
\text { maintain your erection to } \\
\text { completion of intercourse? }\end{array}$} & $\begin{array}{l}\text { DID NOT } \\
\text { ATTEMPT } \\
\text { INTERCOURSE }\end{array}$ & $\begin{array}{l}\text { EXTREMELY } \\
\text { DIFFICULT }\end{array}$ & $\begin{array}{l}\text { VeRY } \\
\text { DifFICULT }\end{array}$ & DIFFICULT & $\begin{array}{l}\text { SLIGHTLY } \\
\text { DifFICULT }\end{array}$ & $\begin{array}{l}\text { Not } \\
\text { Difficult }\end{array}$ \\
\hline & 0 & I & 2 & 3 & 4 & 5 \\
\hline \multirow[t]{2}{*}{$\begin{array}{l}\text { 5. When you attempted } \\
\text { sexual intercourse, how often } \\
\text { was it satisfactory for you? }\end{array}$} & $\begin{array}{l}\text { DID NOT } \\
\text { ATTEMPT } \\
\text { INTERCOURSE }\end{array}$ & $\begin{array}{l}\text { ALMOST NEVER } \\
\text { OR NEVER }\end{array}$ & $\begin{array}{l}\text { A FEW TIMES } \\
\text { (MUCH LESS } \\
\text { THAN HALF } \\
\text { THE TIME) }\end{array}$ & $\begin{array}{l}\text { SOMETIMES } \\
\text { (ABOUT HALF } \\
\text { THE TIME) }\end{array}$ & $\begin{array}{l}\text { MOST TIMES } \\
\text { (MUCH MORE } \\
\text { THAN HALF } \\
\text { THE TIME) }\end{array}$ & $\begin{array}{l}\text { ALMOST } \\
\text { ALWAYS OR } \\
\text { ALWAYS }\end{array}$ \\
\hline & 0 & I & 2 & 3 & 4 & 5 \\
\hline
\end{tabular}

Add the numbers corresponding to questions I-5.

TOTAL:

The Sexual Health Inventory for Men further classifies ED severity with the following breakpoints:

$\begin{array}{llll}\text { I-7 Severe ED 8-I I Moderate ED } & \text { I2-I6 Mild to Moderate ED } & \text { I7-2 I Mild ED }\end{array}$

\section{Reference}

1. Rosen R, Riley A, Wagner G, Osterloh I, Kirkpatrick J, Mishra A. The international index of erectile function (IIEF): a multidimensional scale for assessment of erectile dysfunction. Urology. 1997;49(6): 822-830. 
Research and Reports in Urology

\section{Publish your work in this journal}

Research and Reports in Urology is an international, peer-reviewed, open access journal publishing original research, reports, editorials, reviews and commentaries on all aspects of adult and pediatric urology in the clinic and laboratory including the following topics: Pathology, pathophysiology of urological disease; Investigation and treatment of

urological disease; Pharmacology of drugs used for the treatment of urological disease. The manuscript management system is completely online and includes a very quick and fair peer-review system, which is all easy to use. Visit http://www.dovepress.com/testimonials.php to read real quotes from published authors.

Submit your manuscript here: http://www.dovepress.com/research-and-reports-in-urology-journal 